\title{
Storage stability of nucleic acids in the body louse, Pediculus humanus
}

\author{
Si-Woo LeE ${ }^{1)}{ }^{2)}$, Minoru Minara ${ }^{1)}$, Takashi Tomita ${ }^{1)}$ \\ and Shinji KASAI ${ }^{1)}$ \\ 1) Department of Medical Entomology, National Institute of Infectious Diseases, \\ 1-23-1 Toyama, Shinjuku-ku, Tokyo, 162-8640 Japan \\ 2) Division of Entomology, National Institute of Agricultural Science and Technology, \\ 249 Seodun-dong, Kwonseon-ku, Suwon, 441-707 Korea
}

(Received: 8 December 2005; Accepted: 15 March 2006)

\begin{abstract}
Stability of nucleic acids in the body louse preserved under several conditions was investigated in order to explore the ideal stock method of the human louse for molecular diagnosis. The partial DNA sequence of the para-orthologous sodium channel, which is the target site of pyrethroid insecticide, was amplified by utilizing the polymerase chain reaction (PCR) and the stability of genomic DNA and poly $(\mathrm{A})^{+}$RNA in dead insects was evaluated. Overall, poly $(\mathrm{A})^{+}$RNA was less stable than the genomic DNA even if lice were stored in $70 \%$ or in absolute ethanol. Stability of genomic DNA lasted for at least two months when the lice were fixed in $99.5 \%$ ethanol or even in the lice which died of starvation at room temperature without any treatment. On the contrary, apparent degradation of genomic DNA and poly $(\mathrm{A})^{+} \mathrm{RNA}$ was observed for lice, which were killed with vapor of diethyl ether, suggesting that the moisture or blood in the body of louse needs to be dried out or digested naturally before storing insects for molecular analysis.
\end{abstract}

Key words: body louse, preservation, ethanol, molecular diagnosis, stability

\section{INTRODUCTION}

Since the early 1990s head lice infestation is unexpectedly increasing among young children and is becoming a problem in nurseries and elementary schools in Japan (Agui, 1999). One of the most effective control methods of head lice, at present, is the use of insecticide in this country. Historically and universally, continuous use of pediculicide led to development of resistance and resulted in difficulty of head lice control (Tomita, 1999). Therefore, it is important to monitor the status of insecticide susceptibility of head lice and survey the effective use of the insecticide to children, the major users of pediculicide. Lately, we established a rapid and convenient bioassay method for the head louse (Kasai et al., 2003a) and continuously monitored the susceptibility of head lice to phenothrin, which is the only registered and available active ingredient as a pediculicide in Japan. In 2001, we found that three head louse colonies collected in Tokyo developed resistance to phenothrin and it was the first evidence of resistant colonies distributing in this country (Tomita et al., 2003, 2005). Accordingly, nationwide survey of head lice susceptibility to phenothrin is needed to comprehend the current status. Low viability (i.e. high control mortality) of head louse after its removal from a host, however, made it difficult to properly examine insecticidesusceptibility by bioassays. Thereafter, analysis of the target molecule of pyrethroid insecticide, the para-orthologous sodium channel, revealed that the resist- 
Table 1. Oligonucleotide sequences used in this study.

\begin{tabular}{ll}
\hline \hline Name & \multicolumn{1}{c}{ Sequence $\left(5^{\prime} \rightarrow 3^{\prime}\right)$} \\
\hline QT' & CCAGTGAGCAGAGTGACGAGGACTCGTGCTCAAGCTTTTTTTTTTTTTTT \\
R5-PhSC & GTCGTGATGATCCAAAGCC \\
F21-PhSC & GGTTACGAACCCGTATCGAG \\
F21-PhSC & AGCGTCACATTGTAAAGAAGAGG \\
F26-PhSC & TTCGCAATCCTACTCCTGG \\
R29-PhSC & TGTCTCTATCGCGTCCATC \\
\hline
\end{tabular}

ant head lice collected in Japan commonly possessed several amino acid substitutions, which cause resistance to phenothrin (Tomita et al., 2003, 2005). Nowadays, molecular diagnosis of insecticide susceptibility of the head louse is possible based on gene sequence polymorphisms.

Although preservation and stability of DNA and poly $(\mathrm{A})^{+}$RNA (mRNA) have been examined with animal and plant tissues or cells (Doyle and Dickson, 1987; Smith et al., 1987; Post et al., 1993) and even with insects (Fukatsu, 1999), such study for the human louse has not been reported. Unlike mosquitoes and black flies, which need blood meals for the maturation of their ovaries, head- and bodylice require feeding blood more frequently (both males and females need blood several times a day) to live and thus it was speculated that blood in the gut of louse might affect stability of nucleic acids during storage. In this study, we evaluated the preservation condition of the body louse in order to facilitate a nationwide census of pyrethroid resistance.

\section{Materials AND Methods}

\section{Insects}

A laboratory colony of the body lice, NIID strain, was used for all experiments (Kasai et al., 2003b). This strain has been maintained for over 40 years by feeding human blood on the arm of one of the authors (M. Mihara). Adult body lice were fed blood $24 \mathrm{~h}$ before each treatment and were left at $30^{\circ} \mathrm{C}$.

\section{Preservation of lice}

About 40 adult body lice were preserved in a $20-\mathrm{m} l$ glass vial with absolute $(99.5 \%)$ or $70 \%$ ethanol at room temperature $\left(25 \pm 1^{\circ} \mathrm{C}\right)$ for $24 \mathrm{~h}, 7 \mathrm{~d}, 14 \mathrm{~d}, 21 \mathrm{~d}$ and 60 days. Special grade of ethanol was used and $70 \%$ ethanol was prepared by diluting 99.5\% ethanol with double distilled water. As a control, lice were starved to death and left at room temperature $\left(25 \pm 1{ }^{\circ} \mathrm{C}, 60 \pm 5 \%\right.$ humidity) until isolation of nucleic acids. Lice were also compulsorily killed by vapor of diethyl ether and left at the same condition until isolation of nucleic acids.

\section{Preparation of nucleic acids}

Before isolating the nucleic acids, fixed insects were placed on clean tissue paper for a minute to remove the preparative. Individual lice were homogenized with Isogen (Nippon Gene, Japan) by microhomogenizer in a $1.5 \mathrm{~m} l$ plastic tube and the total RNA and genomic DNA was simultaneously isolated as described by the manufacturer. Isolated nucleic acids were dissolved in TE buffer $(10 \mathrm{mM}$ Tris $-\mathrm{HCl}$ and $1 \mathrm{mM}$ EDTA, pH 8.0). Complementary DNA (cDNA) was synthesized with isolated total RNA, reverse transcriptase (ReverTra Ace ${ }^{\mathbb{R}}$ (Toyobo, Japan)) and QT primer (Table 1).

\section{PCR amplification}

Genomic PCR was performed with genomic DNA comprised in the total RNA as a template. Primer sequences used for amplification of genomic DNA or cDNA are listed in Table 1. For the amplification of genomic DNA, F21-PhSC and R24-PhSC 
primers were used. To examine the stability of mRNA, two sets of primer (F26$\mathrm{PhSC} / \mathrm{R} 5-\mathrm{PhSC}$ and F26-PhSC/R29-PhSC) were used. These primers were designed from the para-orthologous sodium channel cDNA of the body louse (Tomita et al., 2003). PCR reaction mixtures were heated to $95^{\circ} \mathrm{C}$ for $5 \mathrm{~min}$, then put through 35 cycles of PCR amplification: $95^{\circ} \mathrm{C}$ for $30 \mathrm{~s}$, $52^{\circ} \mathrm{C}$ for $30 \mathrm{~s}$, and $68^{\circ} \mathrm{C}$ for $2 \mathrm{~min}$, followed by $68^{\circ} \mathrm{C}$ for $5 \mathrm{~min}$. The PCR products were electrophoresed in 1.5\% agarose gels in TAE buffer (40 mM Tris-acetate and $1 \mathrm{mM}$ EDTA), stained with ethidium bromide followed by the observation on a UV transilluminator.

\section{Results AND Discussion}

\section{Stability of $m R N A$}

In this study, we simultaneously isolated mRNA and genomic DNA from human louse to properly evaluate storage stability in the insect body. Since we used the PCR technique to evaluate the stability of nucleic acids, independent quantification of genomic DNA and mRNA was needed. In order to eliminate the coamplification of genomic DNA, we noted the long introns locating between the primers used for the PCR. Loughney et al. previously reported that the para-orthologous sodium channel gene locus consists of a minimum of 26 exons distributed over more than 60 $\mathrm{kb}$ of genomic DNA (Loughney et al., 1989). Therefore, we performed a number of PCRs using multiple pairs of primers designed from the sodium channel cDNA of the head louse (Tomita et al., 2003) in order to locate the long introns. Figure 1 represents that DNA fragments were amplified only when cDNA was used as a template. Both primer sets of $\mathrm{F} 26-\mathrm{PhSC} /$ R29-PhSC and F26-PhSC/R5-PhSC generated about 2 and $0.9 \mathrm{~kb}$ of DNA, respectively (Fig. 1). To the contrary, no amplification of DNA was observed when the genomic DNA was used as a template, suggesting that there are certain lengths of introns between these primer sets. Thus,

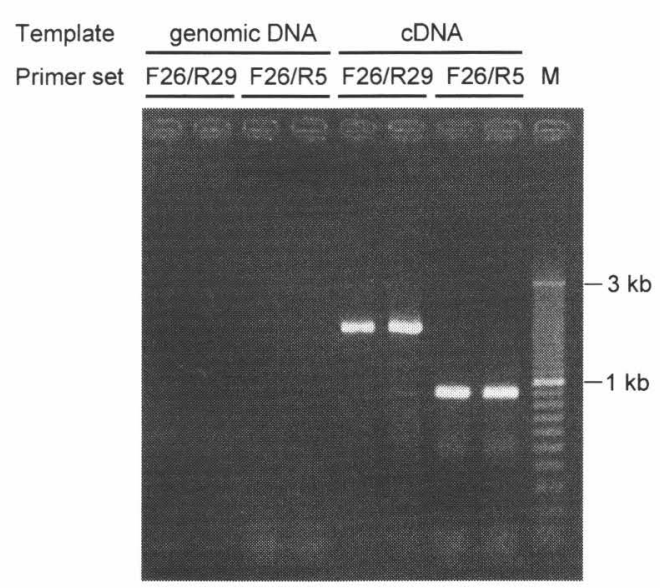

Fig. 1. Effects of long introns on PCR amplification. para-orthologous sodium channel gene of Pediculus humanus was amplified using genomic DNA and cDNA as the template. Nucleic acids were isolated from living adult body lice. Each lane represents amplified DNA fragments of individual body louse. Condition of PCR is described in Materials and Methods. M, standard $100 \mathrm{bp}$ DNA ladder.

using the primer set of F26-PhSC and R29$\mathrm{PhSC}$, we quantitatively checked the stability of mRNA in body lice. Living adult body lice were fixed in 70 and $99.5 \%$ of ethanol up to $24 \mathrm{~h}, 7 \mathrm{~d}$ and $14 \mathrm{~d}$ and mRNA stability in insects was evaluated (Fig. 2). It was obvious that $70 \%$ ethanol was not suitable for fixing lice. Even if lice were fixed in absolute ethanol, apparent degradation of mRNA was observed in 7 d-long preservation suggesting that ethanol is not a suitable solvent for the storage of living louse for a long period. Lice were also killed by vapor of ether and checked for the stability of mRNA, and we hardly succeeded in amplifying the cDNA even from samples prepared $24 \mathrm{~h}$ after the treatment. When lice died of starvation, we could marginally confirm the amplification of the cDNA from the sample of $7 \mathrm{~d}$ after the death but again hardly detected the bands on the day 14 . These results suggest that moisture or blood in the louse may affect stability of mRNA. Nevertheless, our study indicated that mRNA is not a suitable target for diagnosis of phenoth- 


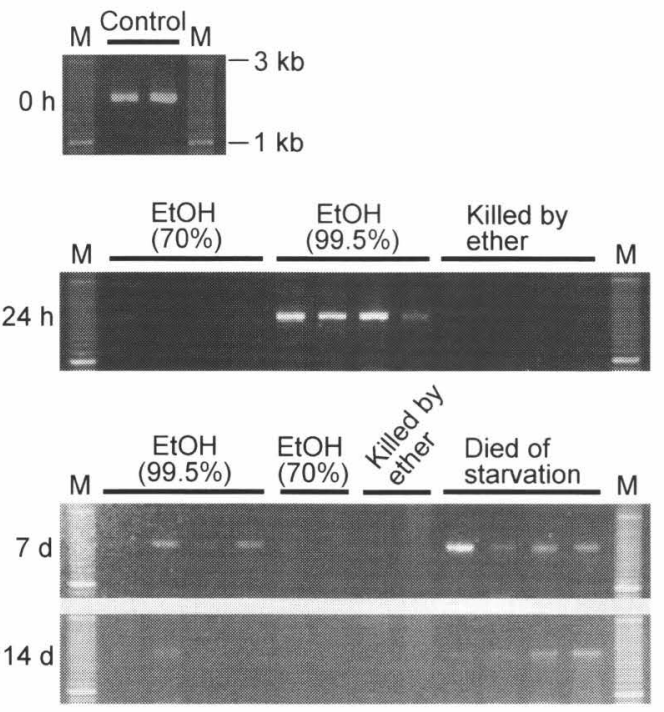

Fig. 2. Stability of mRNA in body lice fixed in ethanol. Body lice which died of starvation or were killed by vapor of diethyl ether were used for isolating mRNA. The samples of mRNA were isolated $24 \mathrm{~h}, 7 \mathrm{~d}$ and $14 \mathrm{~d}$ after treatment and used to synthesize cDNA. Each lane represents amplified DNA fragments of individual body louse. M, standard $100 \mathrm{bp}$ DNA ladder.

rin resistance in the body louse.

\section{Stability of genomic DNA}

Stability of genomic DNA in dead body lice was evaluated by amplification of the para-orthologous sodium channel gene using $\mathrm{F} 21-\mathrm{PhSC}$ and $\mathrm{R} 24-\mathrm{PhSC}$ primers (Table 1). Living body lice were fixed in

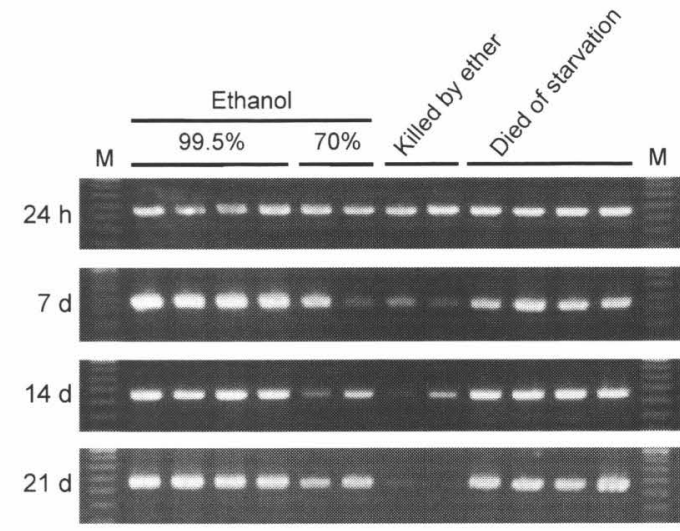

Fig. 3. Stability of genomic DNA in body lice fixed in ethanol. Body lice which died of starvation or were killed by vapor of diethyl ether were used for isolating genomic DNA. The samples of DNA were isolated $24 \mathrm{~h}, 7 \mathrm{~d}, 14 \mathrm{~d}$ and $21 \mathrm{~d}$ after treatment. Each lane represents amplified DNA fragments of individual body louse. M, standard 100 bp DNA ladder.

70 and 99.5\% ethanol and genomic DNA was isolated $24 \mathrm{~h}, 7 \mathrm{~d}, 14 \mathrm{~d}, 21 \mathrm{~d}$ and $60 \mathrm{~d}$ after treatment. As was observed in the study of mRNA, genomic DNA was less stable when lice were fixed in $70 \%$ ethanol than in $99.5 \%$ ethanol (Fig. 3). In absolute ethanol, genomic DNA was stably preserved for no less than two months (Table 2). Lice which died of starvation and were stored at room temperature until used, unexpectedly showed high stability of genomic DNA and the sodium channel gene was sufficiently amplified from the sam-

Table 2. Stability of genomic DNA and mRNA isolated from body lice preserved under the different conditions.

\begin{tabular}{|c|c|c|c|c|c|c|}
\hline Template & Treatment & 24 hours & 7 days & 14 days & 21 days & 60 days \\
\hline \multirow[t]{4}{*}{ cDNA (mRNA) } & EtOH $(99.5 \%)$ & + & \pm & - & NT & NT \\
\hline & EtOH $(70 \%)$ & - & - & - & NT & NT \\
\hline & Killed by ether & - & - & - & NT & NT \\
\hline & Died of starvation & NT & \pm & \pm & NT & NT \\
\hline \multirow[t]{4}{*}{ Genomic DNA } & EtOH $(99.5 \%)$ & + & + & + & + & + \\
\hline & EtOH $(70 \%)$ & + & \pm & \pm & + & NT \\
\hline & Killed by ether & + & \pm & \pm & - & NT \\
\hline & Died of starvation & + & + & + & + & + \\
\hline
\end{tabular}

+ , clearly detected; \pm , detectable; - , hardly detectable or undetectable; NT, not tested 
ples preserved for up to 2 months (Fig. 3, Table 2). This result supports the previous report by other researchers (Vogler and Pearson, 1996). We also sampled genomic DNA from lice which were killed by ether and left at room temperature. Although the sodium channel gene was well amplified from the samples preserved for $24 \mathrm{~h}$ after the treatment, apparent degradation of DNA was observed from samples isolated $7 \mathrm{~d}, 14 \mathrm{~d}, 21 \mathrm{~d}$ and $60 \mathrm{~d}$ after treatment. Unstable preservation of DNA in lice which were killed by ether was consistent with the results for mRNA. These results clearly show that genomic DNA is not stable when lice are forced to die, and thus killing without the death from starvation should be avoided before storage for molecular diagnosis.

\section{Suitable preservation method for human louse}

Originally, the aim of this study was to find reasonable transportation of head lice for molecular diagnosis. Generally, a comb is used to collect living or dead head lice but usually the collection is limited in number. Further, this insect is not so viable once they are removed from a blood source. Thus it is quite difficult to evaluate insecticide susceptibility of the head louse by a conventional bioassay using such a restricted number of insects after transportation, for examination. Lately, we established a convenient molecular diagnostic method to judge susceptibility to pyrethroid insecticide using even a single louse and for this, the nucleic acids of head louse must be stably preserved until use (Tomita et al., 2003, 2005). Fukatsu (1999) reported that acetone is the most reliable and recommendable preservative tested for DNA analysis since this solvent showed high ability of DNA preservation and was more robust against water contamination than ethanol (Fukatsu, 1999). Generally, the sources of this insect, however, are dermatologic hospitals or public health departments. In these facilities, usually, appropriate organic solvents such as acetone or chloroform are not available. Instead in this study, we focused on testing ethanol which is relatively easily obtainable. It is noteworthy that $70 \%$ ethanol (i.e. hydroscopic ethanol) was not a suitable solvent for fixing lice for the test of genomic DNA as well as mRNA. It may suggest that relatively reasonable ethanol solution widely used as an antiseptic reagent (usually made up as approximately $80 \%$ ethanol) at hospitals and other medical institutes is not an appropriate reagent for the storage of body louse. Judging from the above observations, we conclude that for the transportation of head louse at around $25^{\circ} \mathrm{C}$, the insect must have died of starvation without treatment with any organic solvent, or fixed in absolute ethanol in a plastic tube so that the sample can be used for at least two months for the molecular diagnosis targeting for the genomic DNA.

\section{ACKNOWLEDGEMENT}

This work was supported by Grant-inAid for Scientific Research on Emerging and Re-emerging Infectious Diseases from The Ministry of Health, Labour and Welfare (\#H12-Shinkou-33) and for Scientific Research (C) from The Ministry of Education, Culture, Sports, Science and Technology (\#12670245).

\section{REFERENCES}

Agui, N. 1999. Current status of lice infestations as a re-emerging infectious disease. Life Environ., 44: 18-22 (In Japanese).

Doyle, J. and Dickson, E. E. 1987. Preservation of plant samples for DNA restriction endonuclease analysis. Taxon, 36: 715-722.

Fukatsu, T. 1999. Acetone preservation: a practical technique for molecular analysis. Mol. Ecol., 8 1935-1945.

Kasai, S., Mihara, M., Takahashi, M., Agui, N. and Tomita, T. 2003a. Rapid evaluation of human louse susceptibility to phenothrin. Med. Entomol. Zool., 54: 31-36.

Kasai, S., Mihara, M., Takahashi, M., Agui, N. and 
Tomita, T. 2003b. An artificial blood feeding system for body louse, Pediculus humanus. Med. Entomol. Zool., 54: 343-351.

Loughney, K., Kreber, R. and Ganetzky, B. 1989. Molecular analysis of the para locus, a sodium channel gene in Drosophila. Cell, 58: 1143-1154.

Post, R. J., Flook, P. K. and Millest, A. L. 1993. Methods for the preservation of insects for DNA studies. Biochem. Syst. Ecol., 21: 85-92.

Smith, L. J., Braylan, R. C., Nutkis, J. E., Edmundson, K. B., Downing, J. R. and Wakeland, E. K. 1987. Extraction of cellular DNA from human cells and tissues fixed in ethanol. Anal. Biochem., 160: 135138.

Tomita, T. 1999. Insecticide resistance of human lice. Life Environ., 44: 44-48 (In Japanese).
Tomita, T., Yaguchi, N., Mihara, M., Agui, N. and Kasai, S. 2005. Sodium channel point mutations associated with pyrethroid-resistance in the head louse. In: New Discoveries in Agrochemicals (ed. J. M. Clark and H. Ohkawa), ACS symposium series No. 892, pp. 234-243, Oxford University Press, Washington, D.C.

Tomita, T., Yaguchi, N., Mihara, M., Takahashi, M., Agui, N. and Kasai, S. 2003. Molecular analysis of a para sodium channel gene from pyrethroidresistant head lice, Pediculus humanus capitis (Anoplura: Pediculidae). J. Med. Entomol., 40: 468-474.

Vogler, A. P. and Pearson, D. L. 1996. A molecular phylogeny of the tiger beetles (Cicindelidae): congruence of mitochondrial and nuclear rDNA data sets. Mol. Phylogen. Evol., 6: 321-338. 